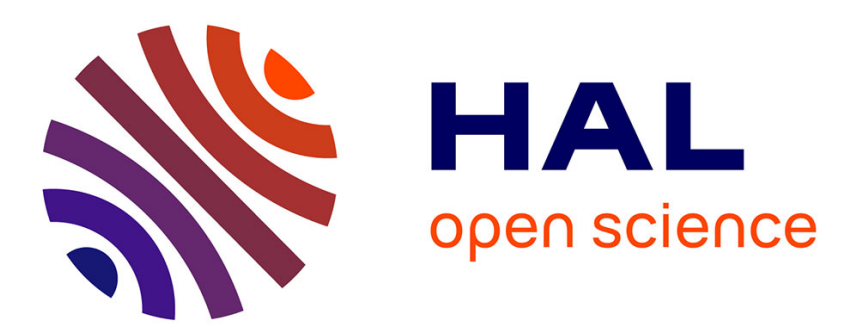

\title{
Electron diffraction and high-resolution transmission microscopy studies of nanostructured Si thin films deposited by radiofrequency dusty plasmas
} Gregorio Viera, Stéphanie Huet, Maxime Mikikian, Laifa Boufendi

\section{- To cite this version:}

Gregorio Viera, Stéphanie Huet, Maxime Mikikian, Laifa Boufendi. Electron diffraction and highresolution transmission microscopy studies of nanostructured Si thin films deposited by radiofrequency dusty plasmas. Thin Solid Films, 2002, 403-404, pp.467. 10.1016/S0040-6090(01)01663-7 . hal00432401

\section{HAL Id: hal-00432401 https://hal.science/hal-00432401}

Submitted on 16 Nov 2009

HAL is a multi-disciplinary open access archive for the deposit and dissemination of scientific research documents, whether they are published or not. The documents may come from teaching and research institutions in France or abroad, or from public or private research centers.
L'archive ouverte pluridisciplinaire HAL, est destinée au dépôt et à la diffusion de documents scientifiques de niveau recherche, publiés ou non, émanant des établissements d'enseignement et de recherche français ou étrangers, des laboratoires publics ou privés. 


\title{
Electron diffraction and high-resolution transmission microscopy studies of nanostructured Si thin films deposited by radiofrequency dusty plasmas
}

\author{
G. Viera, S. Huet, M. Mikikian and L. Boufendi ${ }^{*}$ \\ Groupe de Recherche sur l'Energétique des Milieux Ionisés (GREMI), BP 6744, Université d'Orléans, 45067 \\ Orléans, Cedex 02, France
}

\begin{abstract}
Nanostructured Si thin films, also referred as polymorphous Si, were grown by chemical vapor deposition using modulated radiofrequency (rf) plasmas of $\mathrm{SiH}_{4}$ highly diluted in Ar. The plasma conditions were adapted to obtain a new type of Si thin films between the amorphous and the microcrystalline ones, by allowing the formation of nanocrystalline Si particles in the plasma gas phase and their incorporation into the growing film. These films consist of Si-ordered domains (1-5 nm) embedded in an amorphous matrix, as seen by high-resolution transmission electron microscopy. Films with different crystallite size and density were obtained depending on the plasma modulation and discharge conditions. Selected area electron diffraction has highlighted that such Si-ordered domains are crystals with face-cubic-centered structure, clearly different from the Si diamond-like structure.
\end{abstract}

Keywords: Polymorphous silicon, nanostructured, fcc, RF plasma-CVD, electron microscopy

\section{Introduction}

The term "polymorphous Si" is used to define a new type of Si material that consists of a two-phase mixture of amorphous and ordered Si [1]. These thin films are obtained by plasma-enhanced chemical vapor deposition (PECVD) under a wide variety of plasma conditions, but always allowing the formation of $\mathrm{Si}$ nanoparticles in the plasma gas phase and their contribution to the growing film. Despite the heterogeneity of these films, transport properties have been found to be greatly improved when compared to standard amorphous $\mathrm{Si}(\mathrm{a}-\mathrm{Si}: \mathrm{H})$, thus enhancing their device applications in the solar cell domain [2].

Usually, polymorphous $\mathrm{Si}$ (pm-Si) films are also called hydrogenated nanostructured $\mathrm{Si}$ (ns-Si:H) in agreement with their high hydrogen concentration and with the nanometer size of the Si ordered domains [3]. In the following, we will use the designation of ns-Si:H.

Here, a careful analysis by TEM, HRTEM and electron diffraction is presented with the aim to clarify the specific atomic structure of these films. We have focused on the characterization of Si films deposited by square-wave modulated (SQWM) radio-frequency (rf) plasmas of $\mathrm{SiH}_{4}$ diluted in Ar. Modulation period and process temperature were changed to obtain films with different nanostructures. The results of the present characterization were compared to that found in films deposited in continuous $\mathrm{SiH}_{4}-\mathrm{H}_{2}$ plasmas, and in nanocrystalline $\mathrm{Si}$ powders grown in modulated $\mathrm{SiH}_{4}$-Ar plasmas. Whatever the plasma conditions, the electron diffraction images always reveal the existence of a well-defined crystalline structure different to the diamond-like structure of Si. A new Si face-centeredcubic (fcc) structure is noticed.

\section{Experimental}

n-Si:H thin films were produced in a PECVD reactor by glow discharge decomposition of $\mathrm{SiH}_{4}$ diluted in Ar. The plasma camera was of the circularplate type with horizontal electrodes and rf power excited at $13.56 \mathrm{MHz}$. The gas flow was injected with a showerhead type rf powered electrode. The rf power source was SQWM to control the powder size. SQWM consists of alternating plasma-on periods $\left(T_{O N}\right)$, during which a film is deposited on the anode and particles are formed in the plasma gas phase, with afterglow periods $\left(T_{O F F}\right)$, during which the particles leave the plasma and can contribute to film deposition. $T_{O F F}$ was

\footnotetext{
* Corresponding Author: Tel. (33)(0)2 384948 73; Fax. (33)(0)2 3841 71 54; E-mail: laifa.boufendi@univ-orleans.fr
} 

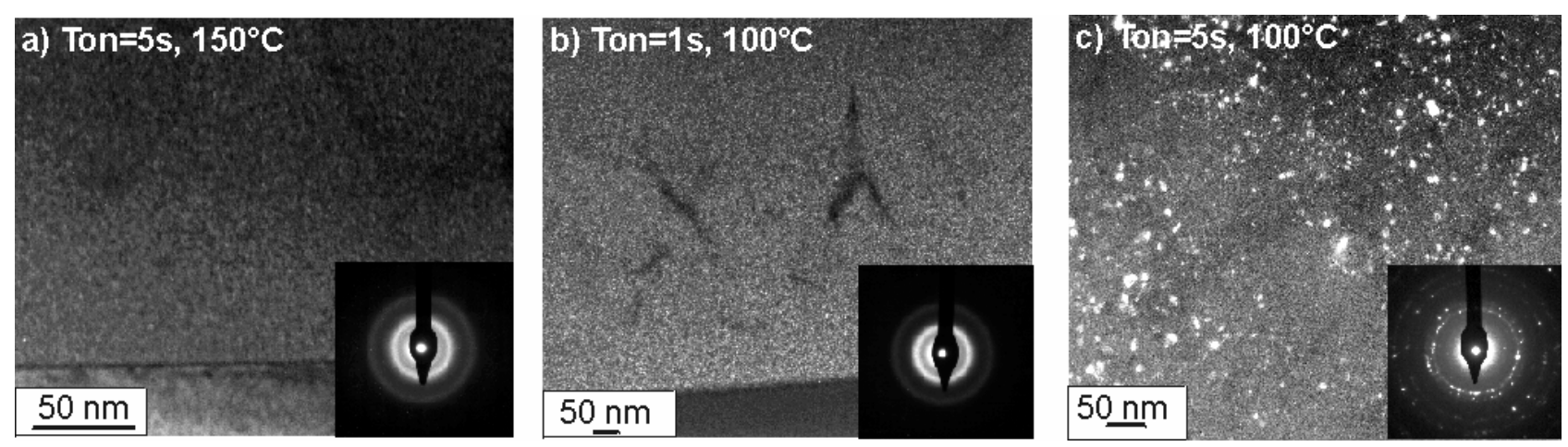

Figure 1. Dark-field images of as-deposited pm-Si:H films grown in rf plasmas of Ar-diluted $\mathrm{SiH}_{4}$ under different dustforming conditions: a) $\mathrm{T}_{\mathrm{ON}}=5 \mathrm{~s}$ and $\mathrm{T}_{\mathrm{G}}=150^{\circ} \mathrm{C}$; b) $\mathrm{T}_{\mathrm{ON}}=1 \mathrm{~s}$ and $\mathrm{T}_{\mathrm{G}}=100^{\circ} \mathrm{C}$, and $\mathrm{T}_{\mathrm{ON}}=5 \mathrm{~s}$ and $\mathrm{T}_{\mathrm{G}}=100^{\circ} \mathrm{C}$. The inserts in the images show the corresponding selected area electron diffraction patterns.

long enough to restore the initial conditions of the gas in each new cycle. On the basis of previous studies on the formation of Si powder particles [4], we chose the following parameters: $30 \mathrm{sccm}$ of Ar, $1.2 \mathrm{sccm}$ of $\mathrm{SiH}_{4}$, total pressure of $12 \mathrm{~Pa}$, rf power density of 60 $\mathrm{mW} / \mathrm{cm}^{2}$, and gas temperature of $100^{\circ} \mathrm{C}$. The $T_{O N}$ was varied from 0.1 to $5 \mathrm{~s}$ in order to produce films with different particle size and concentration.

The particle morphology and structure were observed by conventional and high resolution transmission electron microscopy (HRTEM and TEM, respectively) and selected area electron diffraction (SAED), using a Philips CM30 microscope operating at $300 \mathrm{kV}$. The samples were cross-sectional prepared using the conventional thinning method: first they are mechanically polished using abrasive materials and finally thinned with ion milling. The measurements performed on HRTEM and SAED images were previously calibrated from the analysis of the crystalline Si substrate of the $\mathrm{n}-\mathrm{Si}: \mathrm{H}$ thin films.

\section{Results}

Figure 1 shows dark field images of a thin film deposited at $\mathrm{T}_{\mathrm{ON}}=5 \mathrm{~s}$ and $\mathrm{T}_{\mathrm{G}}=150^{\circ} \mathrm{C}$ (Fig. 1a) and those of thin films deposited at the same lower temperature $\mathrm{T}_{\mathrm{G}}=100{ }^{\circ} \mathrm{C}$ but at two different plasma durations $\left(\mathrm{T}_{\mathrm{ON}}=1 \mathrm{~s}\right.$ Fig. $1 \mathrm{~b}$ and $\mathrm{T}_{\mathrm{ON}}=5 \mathrm{~s}$ Fig. $\left.1 \mathrm{c}\right)$. The films deposited at $\mathrm{T}_{\mathrm{ON}}=5 \mathrm{~s}$ and $\mathrm{T}_{\mathrm{G}}=150{ }^{\circ} \mathrm{C}$ appear highly amorphous. This is in agreement with previous studies on particle formation in the plasma
[4]. Therefore, this sample can be taken as a reference for the dark field analysis. The film deposited at $\mathrm{T}_{\mathrm{ON}}=$ $5 \mathrm{~s}$ and $\mathrm{T}_{\mathrm{G}}=100^{\circ} \mathrm{C}$ (Fig. 1c) clearly shows a considerable increase in crystalline density. This is consistent with the emergence of distinct rings in the corresponding electron diffraction pattern (insert in the image).

In order to obtain further information about the size and density of the crystallites in the different pm-Si:H samples, we have used an image processing and analysis software to identify the bright points in the dark-field images (considered as objects) and to extract the features of these objects (quantity, area, perimeter, roundness, etc). By means of this software, the size histograms and the crystalline densities $\mathrm{D}_{\mathrm{C}}$ have been calculated (figure 2). These histograms indicate that the majority of crystallites presents dimensions inferior to $2 \mathrm{~nm}$, with decreasing populations for larger grain sizes. This figure also shows that crystalline density increases when the gas temperature decreases, and even more when plasma duration increases.

Figure 3 shows the HRTEM images of the thin film deposited at $\mathrm{T}_{\mathrm{ON}}=5 \mathrm{~s}$ and $\mathrm{T}_{\mathrm{G}}=150^{\circ} \mathrm{C}$ (Fig. 3a), and of the film deposited at the same temperature $\mathrm{T}_{\mathrm{G}}=100$ ${ }^{\circ} \mathrm{C}$ but at two different plasma durations $\left(\mathrm{T}_{\mathrm{ON}}=1 \mathrm{~s}\right.$ Fig. $3 \mathrm{~b}$ and $\mathrm{T}_{\mathrm{ON}}=5 \mathrm{~s}$ Fig. 3c). The films deposited at higher temperature appear highly amorphous, while the sample deposited at $100^{\circ} \mathrm{C}$ contains many ordered domains limited to 3-5 planes, corroborating the average crystallite size is inferior to $2 \mathrm{~nm}$. This is
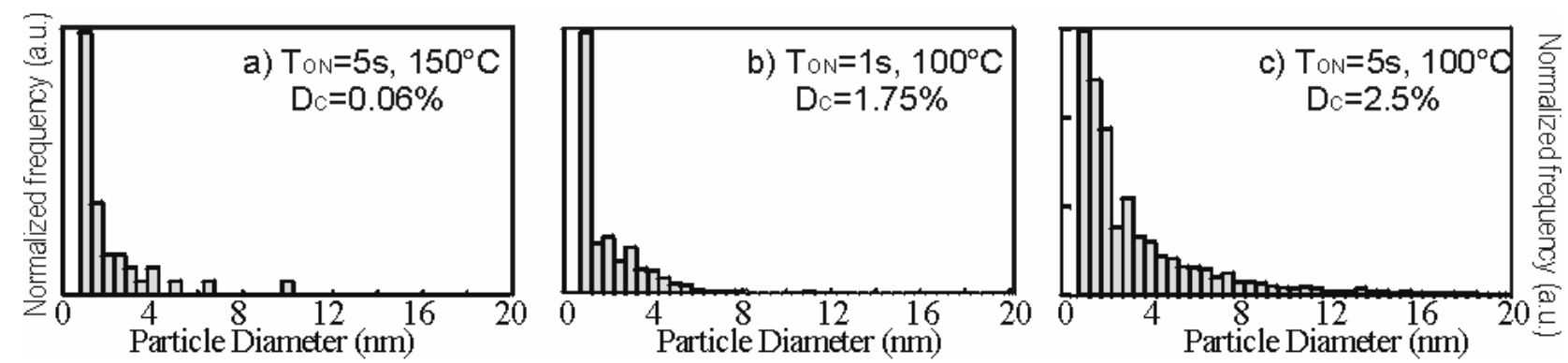

Figure 2. Particle size histograms deduced from the TEM images on dark field of figure 1 . The crystalline density $\left(D_{C}\right)$ was also calculated from the dark field images 

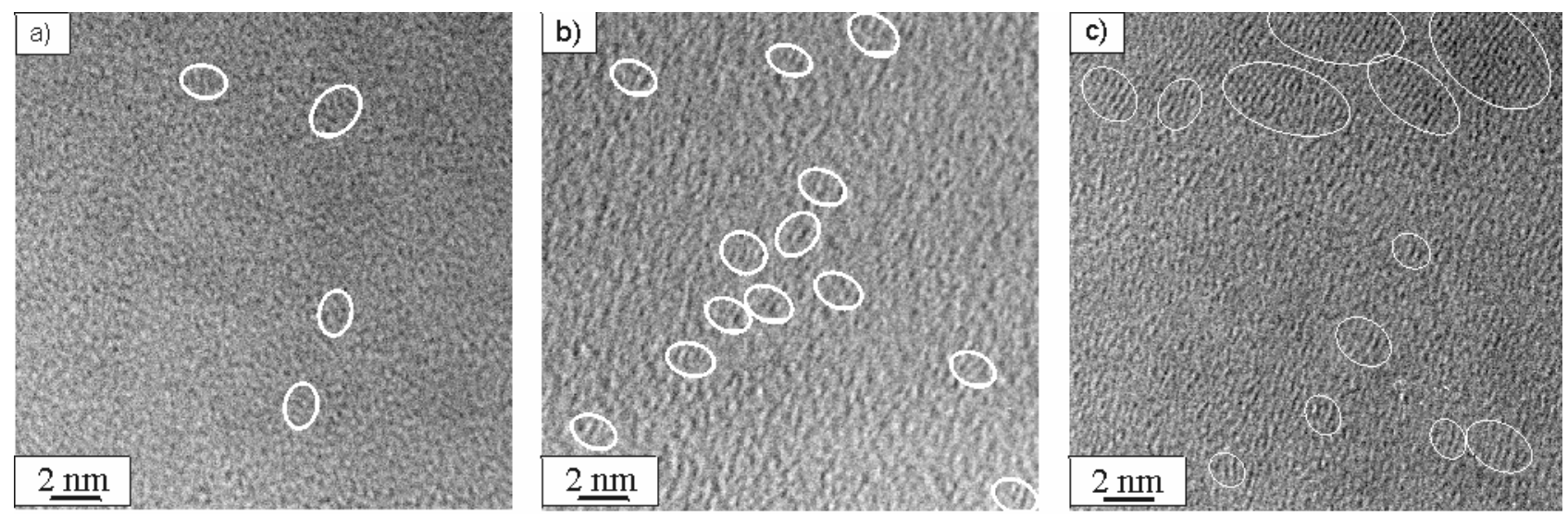

Figure 3. HRTEM photographs of as-deposited pm-Si:H film deposited at (a) $\mathrm{T}_{\mathrm{G}}=150^{\circ} \mathrm{C}$ and $\mathrm{T}_{\mathrm{ON}}=5 \mathrm{~s}$, (b) $\mathrm{T}_{\mathrm{G}}=100^{\circ} \mathrm{C}$ and $\mathrm{T}_{\mathrm{ON}}=1 \mathrm{~s}$ and (c) $\mathrm{T}_{\mathrm{G}}=100^{\circ} \mathrm{C}$ and $\mathrm{T}_{\mathrm{ON}}=5 \mathrm{~s}$. Some of the nanometric ordered domains embedded in the amorphous silicon matrix are surrounded by a white line.

calculated from the dark-field images (some of the ordered domains are surrounded by white circles in the image). The interplanar distances of these domains are 0.3-0.34 nm. The HRTEM image of the sample deposited at $100^{\circ} \mathrm{C}$ but at $\mathrm{T}_{\mathrm{ON}}=5 \mathrm{~s}$ also shows the presence of these small crystalline entities, as well as some larger crystallites up to $5 \mathrm{~nm}$. These observations are commensurate with the results obtained from the dark-field images and do demonstrate the presence of ordered structures in the amorphous Si matrix of the films considered here. Comparable HRTEM images have already been reported for nanostructured Si thin films deposited using continuous rf discharges of $\mathrm{SiH}_{4}$ highly diluted in $\mathrm{H}_{2}$ at $100^{\circ} \mathrm{C}$ and at low rf power [5].

The plasma parameters for the production of these pm-Si:H films were adapted from previous reports devoted to the formation of silicon particles in Ardiluted $\mathrm{SiH}_{4}$ discharges [4]. Three growth phases have been defined:

1. a first step of particle nucleation of around $2 \mathrm{~nm}$, where particle concentration increases while their size remains constant.

2. a second phase of coagulation of particles, which gives rise to larger particles and to a drop in particle concentration.

3. a third phase (from 20-40 nm) where the coagulation is finished and particles grow more slowly by sticking of silicon radicals on their surface.

These studies also showed that the gas temperature plays an important role in the process of particle formation, by delaying the appearance of the initial crystallites and, to a greater extent, the start of their coagulation.

Using the results of Boufendi et al. [4], we have estimated the characteristic times for the onset of particle nucleation $\left(t_{1}\right)$, of coagulation $\left(t_{2}\right)$ and of molecular sticking $\left(t_{3}\right)$ for the three deposition temperatures considered in this study $\left(\mathrm{T}_{\mathrm{G}}=25,100\right.$, $150^{\circ} \mathrm{C}$ ), which are the following:
1. $\mathrm{T}_{\mathrm{G}}=25^{\circ} \mathrm{C}: \mathrm{t}_{1} \approx 0.001-0.01 \mathrm{~s}, \mathrm{t}_{2} \approx 0.15 \mathrm{~s}$ and $\mathrm{t}_{3} \approx 4 \mathrm{~s}$

2. $\mathrm{T}_{\mathrm{G}}=100{ }^{\circ} \mathrm{C}: \mathrm{t}_{1} \approx 0.35 \mathrm{~s}, \mathrm{t}_{2} \approx 2 \mathrm{~s}$ and $\mathrm{t}_{3} \approx 13 \mathrm{~s}$

3. $\mathrm{T}_{\mathrm{G}}=150{ }^{\circ} \mathrm{C}: \mathrm{t}_{1} \approx 1 \mathrm{~s}, \mathrm{t}_{2} \approx 10 \mathrm{~s}$ and $\mathrm{t}_{3} \approx 20 \mathrm{~s}$

In view of these results, the sample deposited at $150^{\circ} \mathrm{C}$ and $\mathrm{T}_{\mathrm{ON}}=5 \mathrm{~s}$ as well as the sample deposited at $100^{\circ} \mathrm{C}$ and $\mathrm{T}_{\mathrm{ON}}=1 \mathrm{~s}$ could contain only crystallites of a few nanometers coming from the first nucleation stage. This is well demonstrated from the TEM and HRTEM photographs presented in figures 1 and 3 . At this stage of particle development, the particle size remains constant with time while the concentration is known to increase. This fact could also explain why the density of crystallites found in the sample deposited at $\mathrm{T}_{\mathrm{ON}}=1$ $\mathrm{s}$ and $100^{\circ} \mathrm{C}$ is higher than at $\mathrm{T}_{\mathrm{ON}}=5 \mathrm{~s}$ and $150^{\circ} \mathrm{C}$, since the $\mathrm{T}_{\mathrm{ON}}$ used at $100^{\circ} \mathrm{C}$ is more close to the onset time for particle coagulation than the $\mathrm{T}_{\mathrm{ON}}$ used at $150^{\circ} \mathrm{C}$.

In addition, the sample deposited at $100^{\circ} \mathrm{C}$ and $\mathrm{T}_{\mathrm{ON}}$ $=5 \mathrm{~s}$ may be formed by nanoparticles just after the coagulation process. This is in agreement with the TEM image of figure 1c, which shows the presence of larger crystallites. This film contains also smaller particles of 1-2 $\mathrm{nm}$ (figure 2c), identified as a population of particles that started its growth later in the plasma-on period.

It is important to remark that, for the sample deposited at $100^{\circ} \mathrm{C}$ and at $\mathrm{T}_{\mathrm{ON}}=1 \mathrm{~s}$, the $\mathrm{T}_{\mathrm{ON}}$ used is a little smaller than the characteristic coagulation time $\mathrm{t}_{2}$ $\approx 2 \mathrm{~s}$. Therefore, a higher density of nanocrystallites is expected for the corresponding film obtained just before particle coagulation, and this is consistent with the higher crystalline density of the samples deposited at $100^{\circ} \mathrm{C}$ and $\mathrm{T}_{\mathrm{ON}}=5$.

In the insert of each image of figure 1 , the corresponding selected area electron diffraction (SAED) patterns are also shown. The SAED patterns of figures $1 \mathrm{a}$ and $1 \mathrm{~b}$ contain diffuse rings which can be assigned to an amorphous structure. However, for the film obtained at $\mathrm{T}_{\mathrm{ON}}=5 \mathrm{~s}$ and at $\mathrm{T}_{\mathrm{G}}=100^{\circ} \mathrm{C}$, nanocrystalline features can be identified through the 
appearance of sharp rings. This pattern is different from the diamond-like structure of crystalline Si. After indexation, a face-centred-cubic (fcc) structure is revealed, as demonstrated by the appearance of the (111), (200), (220), (311), (331), ..., diffraction rings. The lattice constant deduced from this diffraction pattern is $3.65 \AA$. A similar crystalline structure was found in nanostructured Si thin films deposited under continuous $\mathrm{SiH}_{4}-\mathrm{H}_{2}$ rf plasma [5] and in Si nanometric powder [6], where nanocrystalline clusters with fcc structure were found to be embedded in an amorphous matrix.

Although it is accepted that the diamond structure is not the most stable structure for small Si crystallites of a few number of atoms $(<2 \mathrm{~nm})$ [7], very little information is found in the literature on the particular atomic structure of the nanoparticles created in $\mathrm{rf}$ plasmas. To the authors knowledge, the fcc has not been previously reported for Si nanocrystallites. This phase is generally given as unstable polytype of $\mathrm{Si}$ which can be obtained under high pressures [8].

The existence of the fcc crystalline lattice in the nanostructured Si thin films is not evident to explain. Other authors have also identified a lonsdaleite phase (hexagonal close-packed, hcp) [9]. The existence of stable phases for nanocrystalline $\mathrm{Si}$ which are usually metastable or unstable for macroscopic bulk silicon is commonly related to size effects. Moreover, other factors related to the process of particle formation by rf plasma, such as the process temperature, pressure and the inert gas dilution, may play an important role in the reconstruction of the particle structure. In addition, ns-Si:H films are highly hydrogenated [6] and the saturation of the crystallite surface with hydrogen can also influence the most stable structure.

Of very important relevance is the high similarity which exists between the hcp and fcc phases. Besides their identical packing fraction (0.74), coordination number (12), and relative nearest-neighbor (1.296, normalized to the distance in the diamond lattice), the two phases present a very similar total structural energy. When compared to the energy of the diamond structures, the difference of structural energy between the three structures is smaller than $10 \%$ [8]. The formation of anyone of these structures under particular conditions of crystal nucleation should not then be privileged. Therefore, it is reasonable that we have observed the formation of Si crystallites with fcc, while other authors had obtained samples grown by the same technique but with the hcp structure. Further research is now being undertaken to clarify the atomic structure of these polymorphous Si thin films [10].

\section{Conclusions}

TEM and HRTEM analysis on ns-Si:H thin films grown in dust-forming rf plasmas of $\mathrm{SiH}_{4}$ diluted in $\mathrm{Ar}$ agrees with previous growth kinetic studies on $\mathrm{Si}$ nanoparticles in these plasmas, and corroborates the hypothesis that ns-Si:H films come from the simultaneous deposition of radicals and particles. Silicon crystallites of the fcc phase were clearly identified using selected area electron diffraction

\section{Acknowledgments}

This study was financed by the European Community under contract "H-Alpha Solar" N. ERK6CT-1999-00004 and partially supported by CICYT, MAT99-0569-CO2-01 of the government of Spain (which is coordinated by Prof. Enric Bertran from the group FEMAN of the University of Barcelona). The authors thank to Juan Carlos Ferrer (from the Serveis Cientifico-Tecnics of the University of Barcelona) for their collaboration with the TEM measurements, and to Dr. Alain Pineau for helpful discussions on the electron diffraction patterns.

\section{References}

[1] P. Roca i Cabarrocas, MRS Symp. Proc. 507 (1998), 855

[2] R. Butté, S. Vignoli, M. Meaudre, R. Meaudre, O. Marty, L. Saviot, P. Roca i Cabarrocas, J. Non-Cryst. Solids 266-269 (2000) 263

[3] G. Viera, P. Roca i Cabarrocas, J. Costa, S. Martinez, E. Bertran, MRS Symp. Proc. 507 (1998) 933

[4] L. Boufendi, J. Herman, A. Bouchoule, B. Dubreil, E. Stoffels, W.W Stoffels, M.L. deGiorgi, J. Appl. Phys. 76 (1994) 148

[5] E. Bertran, S. N. Sharma, G. Viera, J. Costa, P. St'ahel and P. Roca i Cabarrocas, J. Mater. Res. 13 (1998) 2476

[6] G. Viera, E. García-Caurel, J. Costa, J.L. Andújar, E. Bertran, Appl. Surf. Sci. 144 (1999) 702

[7] J.R. Chelikowsky, J.C. Phillips, Phys. Rev. Lett. 63 (1989) 1653

[8] A.Y. Liu, K.J. Chang and M. L. Cohen, Phys. Rev. B 37 (1988) 6344

[9] A. Fontcuberta i Morral, J. Bertomeu, P. Roca i Cabarrocas, J. Non-Cryst. Solids. 266-269 (2000) 48

[10] G. Viera, M. Mikikian, E. Bertran, P. Roca i Cabarrocas, L. Boufendi, submitted to Phys. Rev. B (2001) 